\title{
An Examination of the Structure of the Career Decision Self-Efficacy Scale (Short Form) Among Italian High School Students
}

Journal of Career Assessment 00(0) I-II

(C) The Author(s) 2012 Reprints and permission: sagepub.com/journalsPermissions.nav DOI: $10.1177 / 1069072712471506$ http://jca.sagepub.com

(SAGE

\author{
Alessandro Lo Presti ', Francesco Pace ${ }^{2}$, Marina Mondo ${ }^{3}$, Laura Nota ${ }^{4}$, \\ Provvidenza Casarubia ${ }^{2}$, Lea Ferrari ${ }^{4}$, and Nancy E. Betz ${ }^{5}$
}

\begin{abstract}
This study aims to evaluate the factor structure of Career Decision Self-Efficacy scale-short form in a sample of Italian high school adolescents. confirmatory factor analysis (CFA) was used to test the degree to which a one-factor structure and a five-factor structure provided the best fit. In view of available research the five-factor structure was expected to provide the best fit. Moreover, factorial invariance in males and females was tested. It was expected to be invariant across groups. As expected the five-factor structure showed a better fit than the one-factor model and the factorial invariance resulted invariant across boys and girls.
\end{abstract}

\section{Keywords}

career decision making, self-efficacy beliefs, assessment instruments

\section{Introduction}

The Career Decision Self-Efficacy scale (CDSES, Taylor \& Betz, 1983) is a measure of the way people perceive their ability to make educational and vocational decisions. Career decision self-efficacy was originally defined by Taylor and Betz (1983), as an individual's belief that he or she has the ability to complete successfully the tasks related to decision making in relation to his or her career.

\footnotetext{
'Dipartimento di Psicologia, Seconda Università degli studi di Napoli, Caserta, Italy

${ }^{2}$ Dipartimento di Psicologia, Università degli studi di Palermo, Palermo, Italy

${ }^{3}$ Dipartimento di Psicologia, Università degli studi di Cagliari, Cagliari, Italy

${ }^{4}$ Dipartimento di Psicologia, Università degli studi di Padova, Padova, Italy

${ }^{5}$ Ohio State University, Columbus, $\mathrm{OH}$, USA
}

\section{Corresponding Author:}

Laura Nota, Department of Developmental Psychology and Socialization, University of Padua, via Belzoni, 80, 35I3। Padua, Italy

Email: laura.nota@unipd.it 
This particular kind of self-efficacy, anchored in the socio cognitive theory by Bandura (1977, 1997) and more specifically the socio cognitive theory of careers by Lent, Brown, and Hackett (1994), has attracted the attention of many researchers in the last 20 years, mainly because of its central role in the implementation of interventions of vocational guidance and in the assessment of the outcomes of such interventions (Betz \& Luzzo, 1996). The career decision self-efficacy may in fact be increased through some of the methods described by Bandura (1997) such as verbal persuasion (Luzzo \& Taylor, 1994) or attributional retraining (Luzzo, Funk, \& Strang, 1996).

The CDSES is one of the most frequently used scales in the career counseling and vocational guidance consists of 50 items that provide five subscale scores, assessing the degree of confidence that the person has about his or her ability to: Identify resources, constraints, and personal characteristics that might influence their career choices (Self-Appraisal [SA]), collect information on training and employment opportunities and manage them effectively (Occupational Information [OI]), develop lists of priorities on the effective actions to successfully manage their professional development (Goal Selection [GS]), plan the steps needed to realize a vocational project (Planning [PL]), and address difficulties related to their career (Problem Solving [PS]).

The authors defined the five CDSES areas on the basis of by Crites' (1961) theory of career maturity. In the original version, responses were obtained via a 10 -level confidence continuum, which ranged from 0 (no confidence) to 9 (complete confidence). In 1996, Betz, Klein, and Taylor published a short form of the questionnaire (Career Decision Self-Efficacy scale-short form [CDSES-SF]): Including 25 items ( 5 for each factor) with a confidence continuum identical to that of the previous version. In 2005, finally, a version was made with the same number of items but with a 5-level confidence continuum (Betz, Hammond, \& Multon, 2005), which is the one on which we base this work. The five-factor structure postulates the existence of five factors that combine to determine overall career decision self-efficacy (Betz, Klein, \& Taylor, 1996; Miller, Sendrowitz Roy, Brown, Thomas, \& McDaniel, 2009).

Over the years, the CDSES has been administered along with numerous other measures, in order to examine concurrent and construct validity. Negative relationships with Osipow's Career Decision scale (CDS; Osipow, Carney, Winer, Yanico, \& Koschier, 1987), used to assess the levels of indecision in career choices and positive relationships with the Vocational Identity scale (Holland, Daiger, \& Power, 1980), used to assess the clarity of the view of his or her career goals (Betz et al., 2005) have been reported. Gender differences in levels of career decision self-efficacy (Betz \& Klein, 1996; Betz et al, 1996; Chung, 2002; Creed, Patton, \& Watson, 2002; Taylor \& Popma, 1990) have not been reported.

Robbins (1985) reported a moderate positive association with self-esteem $(r=.53)$ and a negative correlation with anxiety $(r=-.24)$. Taylor and Popma (1990) showed a negative association between the scale and vocational indecision $(r=-.51)$ and external locus of control $(r=-.30)$. Luzzo (1993) found a positive relationship between the CDSES total scores and career maturity $(r=.41)$.

Although the five subscales showed adequate internal consistency reliability (Betz et al., 2005; Chung, 2002; Osipow \& Gati, 1998), the five-factor structure has not been definitely confirmed in recent studies: The scales appearing most consistently in factor analyses are 'occupational information' and 'goal selection' (Betz et al., 1996; Hampton, 2005; Nilsson, Schmidt, \& Meek 2002; Taylor \& Popma, 1990). However, many authors have suggested that five subscales be retained for use in career counseling (O’Brien, 2003) and for assessing the effectiveness of interventions (Luzzo \& Day, 1999).

Some studies carried out on cultures other than the United States (Creed et al., 2002; Hampton, 2005) have essentially confirmed that the scale questionnaire is applicable across cultures, but that its structure, especially the postulated five-factor structure, has yet to be consistently found in research. Chaney, Hammond, Betz, and Multon (2007), for example, through the use of exploratory factor analysis, proposed a four-factor structure among a group of African Americans. 
More recently, Miller, Sendrowitz Roy, Brown, Thomas, and McDaniel (2009) have compared the five-factor structure with a one-factor solution and Hampton's (2005) and Creed, Patton, and Watson (2002) three-factor structures. There had been previous support for the loadings of all five subscales on a large general factor (Robbins, 1985; Taylor \& Popma, 1990). In a recent meta-analysis, which included findings from 56 different countries using different versions of the scale, Nilsson et al. 2002 concluded that both the CDSES and the CDSES-SF provided reliable total scale scores but inconsistently reliable subscales.

Thus, the purpose of this study was to evaluate the factor structure of CDSES and its discriminant and concurrent validity. Specifically, we were interested in the degree to which a one-factor structure (Robbins, 1985; Taylor \& Popma, 1990), and a five-factor structure (Betz et al., 1996) provided the best fit in a large sample of Italian students. In view of available research the five-factor structure was expected to provide the best fit. Moreover, considering the contributions by Betz and Klein (1996), Betz et al., (1996), Chung (2002), Creed et al. (2002), and Taylor and Popma (1990), we expected to find factorial invariance in males and females.

As regards discriminant validity, we used the Osipow's CDS (Osipow et al., 1987) which assesses indecision. In that case, like in other studies, we expected to find correlations lower than $|.30|$ as we believe that the constructs involved, albeit very likely related to one another, can be understood as different and somewhat independent (Tinsley \& Tinsley, 1987). As regards concurrent validity we used the How Much Confidence Do I Have in Myself? (Nota, Ferrari, \& Soresi, 2005; Soresi \& Nota, 2003) which assesses self-efficacy. We expected to find correlations higher than $|.30|$ (Tinsley \& Tinsley, 1987).

\section{Method}

\section{Participants}

A total of 3,390 Italian students in their last year of high school were studied $\left(M_{\text {age }}=18.27, S D=.82\right)$. Among them, 1,260 were male and 2,130 female. The sample was composed as follows: 2,159 (63.7\%) Lyceums (a preuniversity high school), 981 (28.9\%) technical institutes (a technical educational curriculum which can lead both to work and university), $208(6.1 \%)$ professional institutes (a technical educational curriculum that prepares students for work as technicians), and 42 (1.2\%) who did not specify this information.

\section{Measures}

CDSES-SF (Betz et al., 1996). Participants completed the Italian version of the measure that comprises 25 items; the response continuum is a 5-point Likert-type scale, ranging from $1=$ disagree at all to $5=$ fully agree. Cronbach's $\alpha$ for the total scale was .89 , while $\alpha$ s for the subscales were: .67 (SA), .58 (OI), .64 (GS), .69 (PL), and .64 (PS). These values are lower than Betz et al. (1996) values: .94 (total scale), .73 (SA scale), .78 (OI scale), .83 (GS scale), .81 (PL scale), and .75 (PS scale).

The CDS (Osipow et al., 1987) was used to assess career certainty and career indecision. The CDS contains 19 items that are rated using a 4-point scale ranging from 1 to 4 . The instrument was translated into Italian and back translated, following Van de Vijver and Hambleton (1996). Two items are averaged to comprise the Certainty scale and the remaining items are averaged to comprise the Indecision scale. In a previous study (Nota, Ferrari, Solberg, \& Soresi, 2007), authors found internal consistency indices of .82 for the Career Indecision scale and .81 for the Career Certainty scale. They also found that the Certainty scale correlated positively (boys: $r=.49$; girls: $r=.45$ ) and the Indecision scale negatively (boys: $r=-.42$; girls: $r=-.38$ ) with the Career Search SelfEfficacy scale (CSES; Solberg et al., 1994). 
How Much Confidence Do I Have in Myself? (Nota et al., 2005; Soresi \& Nota, 2003) was used to measure self-efficacy. This instrument was devised to examine self-efficacy beliefs in one's own ability to make decision about the future, to complete long task like, for example, finishing high school or university, to use one's own abilities in handling school commitments and controlling the negative emotions that may be experienced in transition times. The 20 -item, self-report instrument asked participants to rate the extent to which each statement described their usual way of thinking and behaving, on a 5-point, Likert-type scale $(1=$ does not describe me at all; $5=$ describes me very well). A series of exploratory and confirmatory factor analyses provided support for a four-factor structure, accounting for $51.8 \%$ of the total variance (Nota et al., 2005). The first factor measured Confidence in One's Own Ability of Decision Making ( 7 items; e.g., 'If others knew me better, they would say I am one who strongly believes in his/her decisional abilities'); the second factor measured Confidence in One's Own Ability of Emotional Self-Control (6 items; e.g., 'I can manage my emotions in an efficacious way'); the third factor measured Confidence in One's Own Ability of Completing Tasks and Activities (3 items; e.g., 'If I can't solve a problem the first time I try, I tend to give up'); the fourth factor measured Confidence in One's Own Ability for Dealing Successfully with Different Activities and Situations (4 items; e.g., 'I am so sure of my abilities that sometimes I like to devote myself to very difficult things'). Scale scores were obtained by summing item responses corresponding to each of the four factors, after negatively worded item scores were reversed. Nota, Ferrari, and Soresi (2005) reported adequate coefficient $\alpha$ values ranged between .72 and .84 and test-retest correlations for the four factors ranged between .70 and .83 . As to concurrent validity, correlations higher than .30 were observed with subtests from the CSES (Solberg et al., 1994). Concerning discriminant validity, correlations with CDS (Osipow et al., 1987) subscales were all below .30.

\section{Procedure}

Students were examined during classes. They participated on a voluntary basis. In some cases, the data collection took place during school guidance activities, and was accompanied by a single report for each student. In other cases, the collected data were aggregated and analyzed in a single report to the principal.

The instrument CDSES-SF (Betz et al., 1996) was first translated into Italian, following Van de Vijver and Hambleton's (1996) suggestions for the translation of tests in cross-cultural research, and was then back translated by a native speakers expert in psychological issues. Special attention was dedicated to the items that involved the major selection. In our scholastic and academic system, people do not choose a specific major but a field of interest. So, we opted for a translation that represented this situation. In the Item 2, the world major was substitute with 'field of study' and majors with 'study courses,' in the Items 13, 20, and 25 the world major was substitute with 'field of study,' and in the Item 4 with 'sector of study,' in the Item 7 with 'study course,' in Item 8 with 'scholastic.'

\section{Data Analysis}

Since the objective of this article is to test the invariance of CDSES across different groups, CFA will be used to develop alternative measurement models that subsequently will be compared (estimation method: Weighted least squares) using Lisrel 8.20.

According to Gregorich (2006), there are five different invariance levels when measures are administered across groups. Specifically, dimensional invariance, which simply requires that an instrument represents the same number of common factors across groups. It is important to note that this form of invariance is only concerned with the number of factors in each group, not the specific 
Table I. Subsample $(N=2,910)$ Comparison of the Two Alternative Factorial Structures

\begin{tabular}{lccccccc}
\hline & $\chi^{2}$ & $d f$ & RMSEA & NNFI & CFI & AIC & CAIC \\
\hline One factor & $1,501.96$ & 275 & .045 & .96 & .96 & $1,601.96$ & $1,936.54$ \\
Five factors & $1,380.59$ & 265 & .044 & .96 & .97 & $1,500.59$ & $1,902.09$ \\
\hline
\end{tabular}

Note. $\mathrm{AIC}=$ Akaike information criterion; $\mathrm{CAIC}=$ consistent version of $\mathrm{AIC} ; \mathrm{CFI}=$ comparative fit index; $\mathrm{NNFI}=$ non normed fit index; RMSEA = root mean square error of approximation.

configuration of items and factors; configural invariance requires that each common factor is associated with identical item sets across groups; metric invariance requires corresponding factor loadings to be equal across groups. This level of invariance provides evidence that corresponding common factors have the same meaning across groups; strong factorial invariance (also known as scalar invariance) requires the equivalence of item intercepts across groups. According to Gregorich: Forces that are unrelated to the common factors such as cultural norms may systematically cause higher or lower valued item response in one population group compared with another. This could lead to the contamination of estimates of group mean differences; finally, strict factorial invariance (also known as residual invariance) requires that corresponding item residual variances are invariant across groups.

The comparison between pairs of models is made using goodness of fit indices. The easiest way to make such a comparison would be to subtract the two values of chi-square obtained and to test this value with respect to the critical value associated with the difference between the two degrees of freedom values (Bentler \& Bonnett, 1980; Long, 1983) but because chi-square is sensitive to sample size (in the sense that returns unreliable values for numerous samples), we will rely on indices not affected by this problem (Cheung \& Rensvold, 2002). The RMSEA (root mean square error of approximation; Steiger, 1990) takes into account the approximation error in the population, that is the lack of fit of the model to the population's covariance matrix; values equal to or less than .05 indicate excellent fit, values between .05 and .08 indicate acceptable fit (Browne \& Cudeck, 1993). The comparative fit index (CFI; Bentler, 1990) assesses the degree of improvement in the model's goodness of fit in relation to the goodness of fit of a null model, in which the correlations between the variables are equal to 0 ; values above .90 indicate good fit of the model. The final fit index is the non normed fit index (NNFI; Tucker \& Lewis, 1973), for which values above .90 indicate good fit of the model. Moreover, we followed the indications of Cheung, Leung, and Au (2006) and Diamantopoulos and Siguaw (2000) who suggest using the Akaike information criterion (AIC) or the consistent version of AIC (CAIC). Lower value means a better model.

To compare nested models, given it is impossible to rely on classic tests of chi-square difference and degrees of freedom, we will utilize the critical difference between the values of CFI (CFI $\Delta$ ) as suggested by Cheung and Rensvold (2002) and Vandenberg and Lance (2000). In particular, an increase in CFI $\Delta$ equal to .01 or less means that the assumption of invariance is valid; when the increase in the CFI $\Delta$ is between .01 and .02 there may be some differences; finally, when the change in the CFI $\Delta$ is greater .02 there are significant differences across groups.

\section{Result}

First of all, we randomly extracted from our sample a subsample of 2,190 participants (in order to have a second subsample of 1,200 students for subsequent analyses: 600 boys and 600 girls); we carried out a confirmatory factor analysis on their responses to compare the one-factor model against the five-factor model. The remaining 1,200 participants, comprised an equal number of boys $(N=600)$ and girls $(N=600)$ and were used for testing factorial invariance. Table 1 depicts our results. 
Table 2. Factorial Invariance Test Between Boys $(N=600)$ and Girls $(N=600)$

\begin{tabular}{lcccccc}
\hline & $\chi^{2}$ & $d f$ & RMSEA & NNFI & CFI & CFI $\Delta$ \\
\hline Configural invariance & 1898.52 & 530 & .066 & .93 & .94 & \\
Metric invariance & 1993.95 & 555 & .066 & .93 & .94 & .00 \\
Strong factorial invariance & 2217.27 & 580 & .069 & .93 & .93 & .01 \\
Strict factorial invariance & 2217.40 & 605 & .067 & .93 & .93 & .01 \\
\hline
\end{tabular}

Note. $\mathrm{CFI}=$ comparative fit index; RMSEA = root mean square error of approximation.

All factorial models show acceptable goodness of fit indexes. The value of the RMSEA is lower and the CFI is higher in the five-factor structure than that for the one-factor alternative. AIC and CAIC are lower in the five-factor model than in the one-factor model, and allow us to assert the first solution is better than the second.

Subsequent tests of factorial invariance were carried out with concern to the five-factor solution. Then, we tested for the equivalence of the five factor CDSES solution among boys $(N=600)$ and girls $(N=600)$ through multiple group analysis. Table 2 depicts our results.

Goodness of fit indexes' values as regards the configural invariance test show adequate values that confirm that the five-factor structure is invariant across groups. Fixing item loadings as regards the test of metric invariance led to a significant chi-square increase, $\chi^{2} \Delta(25)=95.43, p<.001$ but, considering that CFI $\Delta=0$, the metric invariance hypothesis is supported.

Fixing item intercepts resulted in a significant square increase, $\chi^{2} \Delta(25)=223.32, p<.001$; moreover, CFI $\Delta$ is equal to .01 , meaning there are slight but not significant differences across groups. In this case, the scalar invariance was supported, holds, since there were minimal differences in intercept values across groups. Finally, we tested for strict factorial invariance fixing items' error variances. Results are similar to the previous comparison, since there is a significant chi-square increase, $\chi^{2} \Delta(50)=223.32, p<.001$, and an increase of .01 as regards to CFI $\Delta$.

We calculated the average variance extracted for each factor, which is the average amount of each item's variance explained by the latent variable: $38.7 \%$ (SA), $32.02 \%$ (OI), 39.52\% (GS), 38.12\% (PL), and $37.75 \%$ (PS). The content of the five factors shows they are the same as the theoretical factors, for this reason we opted for the naming choose by the authors. The following table depicts the item loadings on the five factors, comparing the values of the following study with those by Miller and colleagues (2009), collected on a sample of European Americans (Table 3).

All items, except the 16th, show satisfactory loadings insofar as they exceed the cutoff of .40, generally referred to in the literature as a threshold value (Tinsley \& Tinsley, 1987). The two sets of loadings are remarkable similar, especially given that the Miller et al. (2009) loadings were obtained in a large sample of European Americans versus the Italian individuals sampled herein. Thus, the substantive content of the factors appears robust.

Finally, the zero-order correlation matrix among the five factors is shown in Table 4; intercorrelations between pairs of factors range from a minimum of .47 to a maximum of .67 .

As expected, the correlations of the CDSE-SF and the Indecision scale ranged from -.24 to -.39, those with the Certainty scale range from .28 to .30 , and those with the self-efficacy measure range from .29 to .68 .

\section{Discussion and Conclusion}

The purpose of this study was to evaluate the factor structure of the CDSES-SF. We examined a group of 3,390 Italian students attending the final year of high school. We developed and compared two measurement models through CFA. In particular, in the spirit of a confirmatory approach, we 
Table 3. Present Study's Item Loadings $\left(\Lambda_{x}\right)$ and Comparison With Item Loadings Found by Miller, Sendrowitz Roy, Brown, Thomas, and McDaniel (2009)

\begin{tabular}{|c|c|c|}
\hline & $\begin{array}{l}\text { Present } \\
\text { study }\end{array}$ & $\begin{array}{l}\text { Miller and } \\
\text { colleagues (2009) }\end{array}$ \\
\hline \multicolumn{3}{|l|}{ Self-appraisal } \\
\hline Accurately assess your abilities (5) & .62 & .63 \\
\hline Determine what your ideal job would be (9) & .70 & .76 \\
\hline Decide what you value most in an occupation (14) & .63 & .64 \\
\hline $\begin{array}{l}\text { Figure out what you are and are not ready to sacrifice to achieve your career } \\
\text { goals (18) }\end{array}$ & .54 & .73 \\
\hline Define the type of lifestyle you would like to live (22) & .61 & .61 \\
\hline \multicolumn{3}{|l|}{ Occupational information } \\
\hline Find information in the library about occupations you are interested in (I) & .48 & .50 \\
\hline $\begin{array}{l}\text { Find out the employment trends for an occupation over the next } 10 \text { years } \\
\text { (10) }\end{array}$ & .59 & .64 \\
\hline Find out about the average yearly earnings of people in an occupation (I5) & .49 & .63 \\
\hline Talk with a person already employed in the field you are interested in (19) & .60 & .69 \\
\hline Find information about graduate or professional schools (23) & .65 & .70 \\
\hline \multicolumn{3}{|l|}{ Goal selection } \\
\hline $\begin{array}{l}\text { Select one major (field of study) from a list of potential majors (study courses) } \\
\text { you are considering (2) }\end{array}$ & .68 & .74 \\
\hline $\begin{array}{l}\text { Select one occupation from a list of potential occupations you are } \\
\text { considering (6) }\end{array}$ & .71 & .75 \\
\hline Choose a career that will fit your preferred lifestyle (I I) & .63 & .74 \\
\hline $\begin{array}{l}\text { Make a career decision and then not worry about whether it was right or } \\
\text { wrong (16) }\end{array}$ & .35 & .49 \\
\hline Choose a major (field of study) or career that will fit your interests (20) & .70 & .75 \\
\hline \multicolumn{3}{|l|}{ Planning } \\
\hline Make a plan of your goals for the next 5 years ( 3 ) & .63 & .61 \\
\hline $\begin{array}{l}\text { Determine the steps you need to take to successfully complete your chosen } \\
\text { major (study course; } 7 \text { ) }\end{array}$ & .66 & .75 \\
\hline Prepare a good resume (12) & .54 & .49 \\
\hline $\begin{array}{l}\text { Identify employers, firms, and institutions relevant to your career } \\
\text { possibilities }(2 I)\end{array}$ & .64 & .73 \\
\hline Successfully manage the job interview process (24) & .61 & .57 \\
\hline \multicolumn{3}{|l|}{ Problem solving } \\
\hline $\begin{array}{l}\text { Determine the steps to take if you are having academic trouble with an } \\
\text { aspect of your chosen major (sector of study; } 4 \text { ) }\end{array}$ & .62 & .63 \\
\hline $\begin{array}{l}\text { Persistently work at your major (scholastic) or career goal even when you get } \\
\text { frustrated (8) }\end{array}$ & .60 & .65 \\
\hline Change majors (field of study) if you did not like your first choice (I3) & .58 & .57 \\
\hline Change occupations if you are not satisfied with the one you enter (I7) & .63 & .53 \\
\hline $\begin{array}{l}\text { Identify from reasonable major (field of study) or career alternatives if you are } \\
\text { unable to get your first choice }(25)\end{array}$ & .64 & .72 \\
\hline
\end{tabular}

Note. In italic the Italian adaptation.

proceeded to compare the structures consisting of one (Robbins, 1985; Taylor \& Popma, 1990) and five factors (Betz et al., 1996).

The five-factor structure, on the basis of the proposal by Betz and colleagues (1996), showed better results than the one-factor model; then we proceeded to test the measurement invariance between boys and girls. The measure showed also adequate discriminant and concurrent validity, as was true in other international research studies. 
Table 4. Zero-Order Correlation Matrix

\begin{tabular}{lcccc}
\hline Factors & Occupational information & Goal selection & Planning & Problem solving \\
\hline Self-appraisal & .55 & .67 & .60 & .54 \\
Occupational information & & .56 & .60 & .48 \\
Goal selection & & & .56 & .47 \\
Planning & & & .54 \\
\hline
\end{tabular}

Note. All coefficients are significant to $p<.01$.

It is increasingly evident to those who deal with career guidance that the study of decision making is crucial, since career decision-making difficulties are among the most prevalent vocational problems of individuals (Osipow, 1999). From this point of view, it is increasingly important to possess tools that can identify not so much a generic "indecisiveness," as one or more aspects that characterize the state of individual decision-making difficulties. It is also important to have a measure that is not limited to the exploration of only one period of life (traditionally late adolescence), but of different transitional stages: "Each of these transitions poses the potential for career indecision to occur. The awareness of this lifelong need further increases the need to develop ways to measure and intervene in career decision problems" (Osipow, 1999, p. 147).

The CDSES-SF is a valuable aid in identifying these issues, which, we believe, need to be adequately integrated in a wide spectrum process of consulting: From this point of view we agree with Gati and Amir (2010) when they argue that 'it is therefore obvious that there are no substitutes for the career counselor's expert judgment about the intervention sequence, taking into account the client's unique situation and personal traits' (p. 318), and with Osipow (1999) who, referring to Career Decision Making Self-Efficacy Scale (CDMSES) (Taylor \& Betz, 1983), emphasizes that it "can identify those aspects of the career decision-making process itself in which clients may be deficient. Having done that, emphasis in counseling can be placed on helping individuals acquire the skills needed to progress further in their career decision status' (p. 152).

In our opinion, the availability of an adequately robust questionnaire in the Italian context for the evaluation of self-efficacy in occupational contexts has positive significant implications for research. Since there are many studies which make use of this questionnaire, its application to the Italian context, as well as other scales evaluating other variables traditionally related to the social cognitive theory, may allow a more comprehensive examination of the validity of the social cognitive career theory (SCCT) in the European context. In fact, Lent and Brown (2006) suggest, to facilitate the consolidation of SCCT, to have valid and comparable measures: 'Without sound measures, for example, it is difficult, if not impossible, to establish whether theory discrepant findings are attributable to problems with the theory, flaws in operationalizing it, or both' (p. 13).

Having the opportunity to explore the so-called process efficacy, as the perception of the ability to manage tasks related to preparation, entry, and adaptation to changes in own career paths, will allow us to focus more on what Bandura (1997) calls self-regulatory efficacy, as the perception of the capacity to self-motivate ourselves toward achieving career goals even under adverse conditions such as those related to the economic crisis or due to living within labor markets characterized by different logics than those where SCCT has been theorized. Understanding the unique aspects of this form of self-efficacy, which contains 'features of both process and coping efficacy' (Lent \& Brown, 2006) is an important suggestion for future research.

Limitations of this study include the use of a convenience sample and the absence of an assessment of the test-retest reliability of the questionnaire, moreover including other populations (such as adults, workers, etc.) would have given additional information about the scales' functioning. 


\section{Declaration of Conflicting Interests}

The authors declared no potential conflicts of interest with respect to the research, authorship, and/or publication of this article.

\section{Funding}

The authors received no financial support for the research, authorship, and/or publication of this article.

\section{References}

Bandura, A. (1977). Self-efficacy: Toward a unifying theory of behavioral change. Psychological Review, 84, 191-215.

Bandura, A. (1997). Self-efficacy: The exercise of control. New York, NY: Freeman.

Bentler, P. M. (1990). Comparative fit indexes in structural models. Psychological Bulletin, 107, 238-246.

Bentler, P. M., \& Bonnett, D. G. (1980). Significance tests and goodness of fit in the analysis of covariance structures. Psychological Bulletin, 88, 588-606.

Betz, N. E., Hammond, M. S., \& Multon, K. D. (2005). Reliability and validity of five-level response continuua for the career decision self-efficacy scale. Journal of Career Assessment, 13, 131-149.

Betz, N. E., \& Klein, K. L. (1996). Relationships among measures of career self-efficacy, generalized self-efficacy, and global self-esteem. Journal of Career Assessment, 4, 285-298.

Betz, N. E., Klein, K. L., \& Taylor, K. M. (1996). Evaluation of a short form of the career decision-making self-efficacy scale. Journal of Career Assessment, 4, 47-57.

Betz, N. E., \& Luzzo, D. A. (1996). Career assessment and the career decision-making self-efficacy scale. Journal of Career Assessment, 4, 413-428.

Browne, M. W., \& Cudeck, R. (1993). Alternative ways of assessing model fit. In K. A. Bollen \& J. S. Long (Eds.), Testing structural equation models (pp. 136-162). Newbury Park, CA: Sage.

Chaney, D., Hammond, M. S., Betz, N. E., \& Multon, K. D. (2007). The reliability and factor structure of the Career Decision Self-Efficacy Scale-SF with African-Americans. Journal of Career Assessment, 15, 2, 194-205.

Cheung, G. W., \& Rensvold, R. B. (2002). Evaluating goodness-of-fit indexes for testing measurement invariance. Structural Equation Modeling, 9, 233-255.

Cheung, M. W. L., Leung, K., \& Au, K. (2006). Evaluating multilevel models in cross-cultural research: An illustration with social axioms. Journal of Cross-Cultural Psychology, 37, 522-541.

Chung, Y. B. (2002). Career decision-making self-efficacy and career commitment: Gender and ethnic differences among college students. Journal of Career Development, 28, 277-284.

Creed, P. A., Patton, W., \& Watson, M. B. (2002). Cross-cultural equivalence of the career decision-making self-efficacy scale-short form: An Australian and South African comparison. Journal of Career Assessment, 10, 327-342.

Crites, J. O. (1961). A model for the measurement of vocational maturity. Journal of Counseling Psychology, 8 , 255-259.

Diamantopoulos, A., \& Siguaw, J. A. (2000). Introducing LISREL. Thousand Oaks, CA: Sage.

Gati, I., \& Amir, T. (2010). Applying a systemic procedure to locate career decision-making difficulties. The Career Development Quarterly, 58, 301-320.

Gregorich, S. E. (2006). Do self-report instruments allow meaningful comparisons across diverse population groups? Testing measurement invariance using the confirmatory factor analysis framework. Medical Care, 44, 578-594.

Hampton, N. Z. (2005). Testing for the structure of the career decision self-efficacy scale-short form among Chinese college students. Journal of Career Assessment, 13, 98-113.

Holland, J. L., Daiger, D., \& Power, P. G. (1980). My vocational situation. Odessa, FL: Psychological Assessment Resources. 
Lent, R. W., \& Brown, S. D. (2006). On conceptualizing and assessing social cognitive constructs in career research: A measurement guide. Journal of Career Assessment, 14, 12-35.

Lent, R. W., Brown, S. D., \& Hackett, G. (1994). Toward a unifying social cognitive theory of career and academic interest, choice, and performance. Journal of Vocational Behavior, 45, 79-122.

Long, J. S. (1983). Confirmatory factor analysis. Newbury Park, CA: Sage.

Luzzo, D. A. (1993). Reliability and validity testing of the career decision-making self-efficacy scale. Measurement and Evaluation in Counseling and Development, 26, 137-142.

Luzzo, D. A., \& Day, M. A. (1999). Effects of Strong Interest Inventory feedback on career decision-making self-efficacy and social cognitive career beliefs. Journal of Career Assessment, 7, 1-17.

Luzzo, D. A., Funk, D. P., \& Strang, J. (1996). Attributional retraining increases career decision-making selfefficacy. Career Development Quarterly, 44, 378-386.

Luzzo, D. A., \& Taylor, M. (1994). Effects of verbal persuasion on the career self-efficacy of college freshmen. California Association for Counseling and Development Journal, 14, 31-34.

Miller, M. J., Sendrowitz Roy, K., Brown, S. D., Thomas, J., \& McDaniel, C. (2009). A confirmatory test of the factor structure of the short form of the Career Decision Self-Efficacy scale. Journal of Career Assessment, $17,507-519$.

Nilsson, J. E., Schmidt, C. K., \& Meek, W. D. (2002). Reliability generalization: An examination of the career decision-making self-efficacy scale. Educational and Psychological Measurement, 62, 647-658.

Nota, L., Ferrari, L., Solberg, V. S. H., \& Soresi, S. (2007). Career search self-efficacy, family support, and career indecision with Italian youth. Journal of Career Assessment, 15, 181-193.

Nota, L., Ferrari, L., \& Soresi, S. (2005). 'Quanta fiducia ho in me?': Validazione di uno strumento per l'analisi delle credenze di efficacia a proposito della gestione delle decisioni scolastico-professionali ["How much confidence do I have in myself? Validation of an instrument for the evaluation of the career-decision making self-efficacy beliefs]. TPM-Testing Psicometria Metodologia, 12, 35-54.

O’Brien, K. M. (2003). Measuring career self-efficacy promoting confidence and happiness at work. In S. J. Lopez \& C. R. Snyder (Eds.), Positive psychological assessment: A handbook of models and measures (pp. 109-126). Washington, DC: American Psychological Association.

Osipow, S. H. (1999). Assessing career indecision. Journal of Vocational Behavior, 55, 147-154.

Osipow, S. H., Carney, C., Winer, J., Yanico, B., \& Koschier, M. (1987). The career decision scale (rev. ed.). Odessa, FL: Psychological Assessment Resources.

Osipow, S. H., \& Gati, I. (1998). Construct and concurrent validity of the career decision-making difficulties questionnaire. Journal of Career Assessment, 6, 347-364.

Robbins, S. B. (1985). Validity estimates for the career decision-making self-efficacy scale. Measurement and Evaluation in Counseling and Development, 18, 64-71.

Solberg, V. S., Good, G. E., Nord, D., Holm, C., Hohner, R., \& Zima, N., . . Malen, A. (1994). Assessing career search expectations: development of the career search efficacy scale. Journal of Career Assessment, 2, 111-123.

Soresi, S., \& Nota, L. (2003). Portfolio Clipper per l'orientamento dagli 15 ai 19 anni-Volume II $^{\circ}$ : Autoefficacia e decision making [The portfolio clipper for 15-19 years old adolescents-Self-efficacy and decision making]. Firenze, Italy: ITER-Organizzazioni Speciali.

Steiger, J. H. (1990). Structural model evaluation and modification: An interval estimation approach. Multivariate Behavioral Research, 25, 173-180.

Taylor, K. M., \& Betz, N. E. (1983). Applications of self-efficacy theory to the understanding and treatment of career indecision. Journal of Vocational Behavior, 22, 63-81.

Taylor, K. M., \& Popma, J. (1990). An examination of the relationships among career decision making self-efficacy, career salience, locus of control, and vocational indecision. Journal of Vocational Behavior, 37, 17-31.

Tinsley, H. E., \& Tinsley, D. J. (1987). Use of factorial analysis in counseling psychology research. Journal of Counseling Psychology, 34, 414-424. 
Tucker, L. R., \& Lewis, C. (1973). A reliability coefficient for maximum likelihood factor analysis. Psychometrika, 38, 1-10.

Vandenberg, R. J., \& Lance, C. E. (2000). A review and synthesis of the measurement invariance literature: Suggestions, practices, and recommendations for organizational research. Organizational Research Methods, 3, 1, 4-69.

Van de Vijver, F. J. R., \& Hambleton, R. K. (1996). Translating tests: Some practical guidelines. European Psychologist, 1, 89-99. 